\title{
IMPACTO DO MODELO ESPANHOL DE GESTÃO NA DOAÇÃO, DISTRIBUIÇÃO E TRANSPLANTE DE ÓRGÃOS E TECIDOS EM SANTA CATARINA NO PERÍODO ENTRE 2002 E 2014
}

\author{
Impact of the Spanish management model for donation, distribution and transplantation \\ of organs and tissues in Santa Catarina state between 2002 and 2014
}

\author{
João Luiz Peixer Marchi ${ }^{1}$, Thiago Mamôru Sakae ${ }^{2}$, Flávio Ricardo Liberali Magajewski ${ }^{3}$
}

\section{RESUMO}

Desde que Adão cedeu sua costela para Eva até os anos 1960, quando ocorreu a primeira doação renal bem sucedida no Brasil, o transplante de órgãos desenvolveu-se como medida terapêutica e às vezes única para diversas morbidades. Nos anos 80, a Espanha iniciou o que posteriormente seria chamado de Modelo Espanhol de gestão do sistema de transplantes, colocando esse país como referência mundial nessa área. Objetivo: Estudar aspectos da gestão/coordenação do sistema de transplantes de Santa Catarina (CNCDO-SC) e sua correlação com os resultados nas taxas de notificação, doação e captação de órgãos no estado entre 2002-2014. Método: Estudo ecológico que incluiu toda a população de Santa Catarina com registro de morte encefálica na CNCDO-SC ou que tenha sido beneficiária de transplante de órgão no período estudado, sendo utilizados os prontuários e registros da CNCDOSC e informações obtidas pelo Sistema Nacional de Transplantes. Os indicadores representaram o desempenho do sistema anualmente e foram descritos em taxas médias elaboradas durante o estudo. Foi estabelecida uma divisão entre o período sem efeito da ação considerada (2002-2007) e com o efeito estudado (2008-2014). Resultados: Houve melhora significativa no desempenho associada à implantação do modelo Espanhol, comprovada pela evolução das taxas de variáveis de gestão que apresentaram forte correlação positiva com as taxas de resultado (notificação, doação e captação de órgãos). Houve ampliação da Taxa de Hospitais Notificantes do período pré- e pós-implantação do modelo estudado, com média de 9,44 entre 2002-2007, tendo saltado para 15,25 entre 2008 2014 ( $p<0,001$ ). O número de horas de capacitação passou de 0,38 horas para 6,08 horas por 1000 trabalhadores da Saúde após a implementação do novo modelo de gestão. Conclusão: A implantação do Modelo Espanhol de Gestão impactou significativamente nos resultados do sistema de transplante de órgãos em SC.

Descritores: Doação de Órgãos; Doação de Tecidos; Transplante.

\footnotetext{
Institution:

${ }^{1}$ Universidade do Sul de Santa Catarina - UNISUL - Campus Pedra Branca, Curso de Medicina.

2 Universidade do Sul de Santa Catarina - UNISUL, Campus Tubarão, Curso de Medicina.

${ }^{3}$ Universidade do Sul de Santa Catarina - UNISUL, Campus Tubarão e Pedra Branca, Curso de Medicina.
}

\section{Correspondence:}

Flávio Ricardo Liberali Magajewski

End.: UNISUL, Campus Tubarão - Curso de Medicina

Av José Acácio Moreira, 787, CEP 88704-900 -Tubarão/SC, Brasil. Tel.: +55 (48) 3621-3950

E-mail: magajewski@hotmail.com

Recebido em: 01/03/2017

Aceito em: 29/04/2017

\section{INTRODUÇÃO}

Diversos são os relatos que compõem a dimensão mítica associada ao surgimento dos transplantes. O primeiro deles encontra-se na Bíblia, com Adão como primeiro doador. Outro relato faz menção a dois médicos chineses, Itoua To e Pien Tsio, gêmeos que estudaram medicina na Grécia. Conta-se que esses dois médicos transplantaram uma perna de um soldado negro que acabara de falecer em outro homem, branco, que tinha sido obrigado a amputar umas das pernas no mesmo dia. ${ }^{1}$ 
Essas histórias, mais do que lendas, expressam a dimensão humana do sonho e da ousadia que sempre cercou o tema das terapias e intervenções médicas orientadas pelo objetivo ambicioso de vencer pela substituição de um órgão doente, a doença e a morte iminente. ${ }^{1}$

O sangue foi o primeiro componente orgânico humano a ser utilizado em outro, tornado possível apenas após a descoberta dos tipos sanguíneos e pela enorme demanda por sangue decorrente das necessidades de inúmeros soldados feridos nas guerras no final do século XIX e início do século $X X$, que exigiu, inclusive, a organização de bancos de sangue e o desenvolvimento de novas tecnologias de conservação e armazenamento. ${ }^{2}$

Entretanto, a linha de base para o transplante de órgãos em bases científicas e com viabilidade técnica começou na década de 1950, com a contribuição dos cirurgiões Aléxis Carrel e Charles C. Guthrie, que criaram a técnica de rafia dos vasos sanguíneos. ${ }^{2}$

Os anos seguintes foram dedicados à resposta imunológica, com o surgimento de novos imunossupressores. Em 1983, com a sintetização da ciclosporina, o transplante de órgãos passou de curiosidade para terapia efetiva. ${ }^{1}$

No Brasil, essa prática teve início nos anos 60 , com a realização de dois transplantes renais, um em São Paulo e outro no Rio de Janeiro. ${ }^{3}$

Após a superação de questões éticas e a consagração do princípio de que os órgãos removidos de cadáveres eram "bens públicos", a necessidade de regulamentar a atividade de transplante, criar uma coordenação nacional e definir critérios mais claros e equânimes para o destino desses órgãos no país foi gradualmente incorporando-se ao arcabouço normativo do Sistema Único de Saúde (SUS). ${ }^{3}$

Em 1997, com a publicação da Lei do Transplante (Lei $n^{\circ}$ 9.434, de 4 de fevereiro de 1997), que regulamentou e instituiu no Brasil o Sistema Nacional de Transplantes (SNT), o país definiu as bases para o desenvolvimento de uma rede moderna de serviços especializados na gestão do processo de doação e transplante, que inclui identificação do potencial doador, diagnóstico de Morte Encefálica (ME), manutenção do potencial doador, autorização familiar para a doação dos órgãos, captação destes e sua distribuição para utilização em um receptor cadastrado. $^{3}$

O transplante é um tratamento médico que consiste na substituição de um órgão ou tecido doente do paciente receptor por outro sadio de um doador vivo ou falecido. ${ }^{4-10}$

O Brasil possui uma das maiores políticas públicas de transplante de órgãos do mundo, tendo como carro- chefe a gratuidade da doação, a beneficência em relação ao receptor e a não maleficência em relação ao doador vivo, mas muitos entraves ainda afetam seus resultados, salientando-se a subnotificação da ME, manutenção inadequada do potencial doador, recusa familiar e deficiências de logística. ${ }^{5}$

O SUS financia $95 \%$ dos gastos relacionados ao transplante de órgãos, incluindo os procedimentos e as medicações imunossupressoras pós-transplantação. ${ }^{6}$

Uma autorização judicial é requerida nos casos de doação entre pessoas sem grau de parentesco. Para transplantes intervivos com até $4^{\circ}$ grau de parentesco, a autorização judicial não é necessária. Todo o sistema é administrado pelas Secretarias Estaduais da Saúde com listas individuais regionais, supervisionadas pelo Ministério Público. ${ }^{6}$

Com ênfase na educação e capacitação dos profissionais que atuam em todo o processo de notificação, doação e utilização de órgãos, Santa Catarina tem se destacado no ranking nacional como o estado com maiores índices de doação de órgãos para transplante, passando de 17,4 doadores pmp em 2010 para 32,3 em 2014. ${ }^{7}$

Tais índices só foram possíveis graças à gestão eficaz da política nacional de transplantes executada pela Secretária de Estado da Saúde, responsável pela administração da Central de Notificação, Captação e Distribuição de Órgãos e Tecidos de Santa Catarina (CNCDO-SC). Segundo a coordenação da SCTransplantes, esses resultados foram obtidos com a adaptação do melhor modelo de gestão do mundo, o Espanhol, que atingiu a marca de 35 doadores pmp (por milhão da população) em $2014 .^{7}$

O modelo espanhol baseia-se na coordenação de transplantes em três níveis: nacional, autônomo e hospitalar. ${ }^{7-9}$ As coordenações nacionais e autônomas, financiadas pela administração sanitária nacional (equivalente ao Ministério da Saúde no Brasil) mantém uma ligação com os níveis políticos, administrativos e profissionais ligados aos transplantes. O nível hospitalar refere-se à coordenação intra-hospitalar - que no Brasil corresponde às Coordenações Intra-Hospitalares de Doação de Orgãos e Tecidos para Transplante (CIHDOTTs), uma equipe multidisciplinar coordenada por um médico intervencionista do próprio hospital e capacitada para todas as atividades relacionadas ao processo de doação e transplante (detecção e manutenção de potenciais doadores, entrevista familiar, apoio à família, etc). ${ }^{10-14}$

Esse modelo prevê uma remuneração para os profissionais envolvidos com o processo de doação e transplante, e um método eficaz de auditoria em todo o protocolo de $\mathrm{ME}$ notificado à CNCDO. ${ }^{14}$ 
A Espanha ocupa lugar privilegiado no nível mundial, com uma das maiores taxas de doação, variando em torno de 33-35 doadores pmp. ${ }^{11-14}$

O Modelo Espanhol de gestão de transplantes de órgãos e tecidos goza de grande prestígio mundial e vem sendo estudo e adaptado em vários países. Vários fatores são destacáveis para explicar esse fenômeno, sendo um dos principais a profissionalização de todo o processo de doação. ${ }^{10}$

O surgimento de técnica de ventilação artificial obrigou os governos a reavaliarem seus conceitos de morte, que anteriormente baseava-se simplesmente em uma parada cardiorespiratória. ${ }^{11}$

Segundo o modelo espanhol, toda legislação relativa à doação de órgãos deveria incluir os seguintes critérios: -Critérios legais e éticos relacionados à ME cujo diagnóstico seja preciso;

-Respeito à vontade do falecido, segundo seu desejo de ser doador ou não;

- Caráter puramente altruísta do processo de doação;

-Anonimato do doador;

- Uso de critérios técnicos na distribuição aos pacientes na fila de espera. ${ }^{11}$

A doação de órgãos entre pessoas vivas limita-se a pessoas capazes civilmente (excluindo os incapazes e os menores de idade), tendo em mente a necessidade de adaptar as informações e os documentos do processo de doação, em caso de incapacidade gerada por doença. ${ }^{12}$

A norma espanhola distingue os casos em que manobras de reanimação cardiopulmonares devem ser feitas ou não por razões médicas e éticas, o que remete à classificação de Maastricht de doadores em morte circulatória. $^{13}$

No Brasil, a ME deve ser registrada no prontuário médico e em um Termo de Declaração de ME, com a descrição do exame neurológico que evidencia a ausência de reflexos do tronco e prova gráfica complementar que evidencie ausência de fluxo sanguíneo cerebral, atividade elétrica e/ou metabólica. ${ }^{15}$

O diagnóstico de ME exige algumas condições: o paciente deve ter registro hospitalar, a causa do coma deve ser estabelecida e o paciente não pode estar em hipotermia $\left(<35^{\circ} \mathrm{C}\right)$, sob uso de drogas depressoras do SNC ou em hipotensão arterial. ${ }^{15}$

Segundo as resoluções do CFM 1480/97 15 e 2173/2017 16, garantidas essas condições, o paciente deve ser submetido a dois exames clínicos neurológicos que avaliarão as funções encefálicas, como nível de consciência e reflexos do tronco cerebral. Após o primeiro ou segundo exame clínico, o paciente deve ser submetido obrigatoriamente ainda a um exame complementar que comprove ausência de perfusão sanguínea, ausência de atividade elétrica cerebral ou ausência de atividade metabólica encefálica.15,16 A resolução 2173 também adicionou a necessidade do tempo mínimo de seis horas para o diagnóstico de ME além de outras modificações em intervalo de avaliações e formação dos médicos examinadores. ${ }^{16}$

A avaliação da qualidade de gestão dos sistemas de transplante e seus resultados e benefícios sociais não é um tema comum na literatura médica. O estudo dessas relações pode esclarecer aspectos do processo de tomada de decisão que contribuam para aperfeiçoamento das funções de coordenação dos sistemas de transplante no Brasil e em outros países, com benefícios sociais significativos que incluam: abordagem mais humanizada dos familiares no momento da morte, aumento do número de doações e de transplantes, redução das perdas por parada cardiorrespiratória durante o processo de diagnóstico da $\mathrm{ME}$, melhoria da qualidade dos órgãos disponibilizados para transplante, aumento da sobrevida dos pacientes transplantados e redução de custos.

O objetivo do presente estudo foi estudar aspectos da gestão/coordenação do sistema de transplantes de Santa Catarina (CNCDO-SC) e sua correlação com os resultados obtidos nas taxas de notificação, doação, captação e utilização de órgãos no Estado no período 2002-2014.

\section{MÉTODOS}

Foi realizado estudo observacional de tipo ecológico. O estudo foi realizado tendo como espaço a gestão da Gerencia de Transplantes - GETRA - instância operacional da CNCDO-SC e responsável pela gestão do sistema de doação, captação, distribuição e transplante de órgãos em Santa Catarina.

A GETRA / CNCDO - SC é uma gerência vinculada à Superintendência de Regulação da Secretaria de Estado da Saúde de Santa Catarina.

Foi estudada a população de Santa Catarina que houvesse sofrido ME com notificação na CNCDO-SC ou tenha sido beneficiária de transplante de órgão ou tecido no período do estudo.

Foram considerados também instituições, servidores públicos e trabalhadores que compuseram o sistema de transplantes de SC que foram alvo de atividades educativas durante o período de 2002-2014.

Foi incluída no estudo toda população transplantada ou que tenha doado órgãos no período de interesse da pesquisa, assim como as atividades de gestão do sistema de transplantes no mesmo período. 
O delineamento da pesquisa tem como objeto a relação entre decisões administrativas e ações de gestão e resultados assistenciais, relação nem sempre fácil ou direta. Por conta desse risco, o maior número possível de indicadores foi coletado para garantir a melhor perspectiva para os testes de associação que foram realizados.

Finalmente, o fato de estudar o universo dos procedimentos relacionados ao processo de doação e transplante que se inicia pela identificação do potencial doador, notificação dos pacientes potenciais doadores diagnosticados com ME, acolhimento e entrevista familiar, segue com a manutenção do paciente até que uma equipe especializada realize a captação e distribuição dos órgãos doados para equipes que finalmente realizarão os transplantes em pacientes em fila de espera, segundo os critérios que incorporam os princípios da universalidade, integralidade e equidade.

Apesar dos cuidados incluídos no delineamento da pesquisa aqui apresentada, não é possível eliminar o principal viés desse tipo de estudo, que é o de "falácia ecológica", ou seja, uma eventual correlação encontrada entre as variáveis estudadas não poderá ser considerada como única explicação para os resultados obtidos, uma vez que inúmeras variáveis eventualmente associadas aos resultados não foram estudadas e/ou controladas.

As variáveis selecionadas para o estudo foram: Hospitais com CIHDOTTs implantadas, Hospitais Notificantes de ME, Macrorregiões de Saúde em SC, Número de servidores treinados pela CNCDO-SC, Número de Horas/Curso oferecidas/ano, Número de Servidores da gestão CNCDO-SC, População de SC, População atuante em área da Saúde em SC, Número de hospitais notificantes de ME em SC, Número de hospitais com UTI em SC, Número de notificações de ME em SC, Número de notificações de PCR em SC, Número de notificações de PCR com captação em SC, Número de recusas pósME em SC, Número de doações confirmadas pós-ME em SC, Número de doações confirmadas pós-ME com captação em SC, Número de Hospitais com CIHDOTTs em funcionamento por ano, Número de membros das CIHDOTTs por ano, Número de CIHDOTTs com gratificação implantada, Número de Transplantes de Rim em SC, Número de Transplantes Rim-Pâncreas em SC, Número de Transplantes de Fígado em SC, Número de Transplantes de Coração em SC, Número de Transplantes de Medula Óssea em SC e Número de Transplantes de Córnea em SC.

Foram utilizados como fontes de dados para a realização desta pesquisa os prontuários e registros da CNCDO$\mathrm{SC}$, os sistemas de informações utilizados pelo Sistema
Nacional de Transplantes e os Sistemas de Informações do SUS.

Os dados de interesse da pesquisa foram transformados em indicadores com a divisão dos produtos considerados para avaliação do desempenho do sistema pela população do estado ou de servidores, conforme o caso, sendo que no primeiro caso, o resultado dessa razão foi multiplicado pela constante 1.000 .000 (milhão de população) e no segundo foi utilizada a constante 100. Os indicadores representaram o desempenho anual do sistema e foram descritos em taxas médias, elaboradas durante o estudo. Conforme o interesse dos pesquisadores, com os valores aferidos, foram calculados a média, o desvio padrão e o intervalo de confiança (IC 95\%); a análise bivariada foi desenvolvida com a aplicação do teste $t$ de Student, sendo $a$ significância definida quando o $p<0,05$.

Em relação às variáveis de gestão, para cada uma foi definido o ano em que foram iniciadas, considerandose esse ano a linha de corte para comparação dos resultados sem o efeito da ação considerada (20022007) e com o suposto efeito dessas ações (2008-2014).

A partir da análise de regressão simples e múltipla, foram identificadas as variáveis selecionadas como ações de gestão e sua correlação com o desempenho do sistema no período estudado.

O projeto foi apresentado aos gestores do sistema estadual de transplante de SC, guardiões das cópias dos prontuários necessários para execução da pesquisa, para autorização do acesso às informações de interesse, após submetido ao comitê de ética em pesquisa envolvendo seres humanos da UNISUL - CEP e aprovado sob protocolo CAAE 51297415.8.0000.5369.

Os benefícios advindos dos resultados obtidos poderão eventualmente contribuir para consagrar iniciativas de gestão que, assumidas por outras CNCDOs de outros estados brasileiros, ampliarão a oferta de órgãos, sua utilização em pacientes com baixa probabilidade de sobrevivência sem a oferta de órgãos e a existência de serviços e transplante capacitados.

\section{RESULTADOS}

Dentre as diversas decisões tomadas pela gestão da CNCDO-SC descritas neste estudo e associadas ao modelo espanhol de gestão, pode-se destacar, conforme a Tabela 1, a ampliação do número de unidades hospitalares qualificadas como hospitais notificantes de potenciais doadores, que foi sintetizada pela criação de uma Taxa de Hospitais Notificantes. Comparando-se essa taxa no período pré e pós- 
implantação do modelo estudado, encontramos a média de 9,44 entre 2002-2007, que saltou para 15,25 entre 2008-2014 ( $p<0,001)$.

Outra iniciativa de gestão associada à implantação do modelo espanhol na CNCDO de Santa Catarina foi a ampliação do número de hospitais em SC com CIHDOTTs estruturadas, que passou de uma média de 7,64 hospitais com CIHDOTTs no período pré-modelo para 16,09 no período pós-modelo $(p<0,001)$.
A ampliação do número de hospitais com CIHDOTTs foi acompanhada pelo crescimento do número de trabalhadores dedicados a ações de doação e captação de órgãos e tecidos. A proporção de trabalhadores nas CIHDOTT para cada 1000 trabalhadores da Saúde passou de 5,84 para 7,54/1000 ( $p<0,001)$.

Entre as iniciativas estruturantes do modelo espanhol, a priorização das atividades de capacitação e treinamento de profissionais ligados às atividades

Tabela 1 - Taxas de qualidade no serviço de transplantes pré e pós-implantação do modelo espanhol na CNCDO. Santa Catarina, 2002-2014

\begin{tabular}{|c|c|c|c|}
\hline $\begin{array}{l}\text { Período } \\
\text { Indicadores de Gestão }\end{array}$ & $\begin{array}{r}\text { 2002-2007 } \\
\text { Taxa e DP } \\
\end{array}$ & $\begin{array}{c}2008-2014 \\
\text { Taxa e DP }\end{array}$ & Valor de $p$ \\
\hline Tx de hospitais notificantes de Morte Encefálica & $9,44 \pm 1,87$ & $15,25 \pm 2,3$ & $<0,001$ \\
\hline Tx hospitais com CIHDOTTs ativas & $7,64 \pm 1,93$ & $16,09 \pm 2,73$ & $<0,001$ \\
\hline Horas de curso / 1000 trabalhadores de saúde & $0,38 \pm 0,77$ & $6,08 \pm 2,88$ & 0,02 \\
\hline Tx de trabalhadores em atividade nas CIHDOTT's/total trabalhadores da saúde & $5,84 \pm 0,35$ & $7,54 \pm 0,36$ & $<0,001$ \\
\hline Tx trabalhadores capacitados das CIHDOTT's & $5,84 \pm 0,35$ & $7,54 \pm 0,36$ & $<0,001$ \\
\hline Tx trabalhadores da CNCDO-SC** & $3,61 \pm 0,78$ & $2,76 \pm 0,7$ & 0,68 \\
\hline
\end{tabular}

Fonte: $\quad$ CNCDO-SC, adaptado pelo autor, 2016

Legenda: ${ }^{\star}$ CIHDOTT - Comissão Intra-Hospitalar de Doação de Órgãos e Tecidos para Transplantes; ${ }^{* *}$ CNCDO-SC - Central Nacional de Captação e Distribuição de Órgãos de Santa Catarina; Tx - Taxa por milhão de população (pmp)

assistenciais em áreas críticas - emergência e UTI - é reconhecida como uma característica marcante. Essa ação foi representada pelo indicador horas/ curso oferecidas, sendo o denominador o número de trabalhadores da Saúde registrados pelo INSS no período estudado.

Apesar do amplo leque de conteúdo oferecido, eles foram predominantemente focados na capacitação dos funcionários integrantes das CIHDOTTs. Comparando a evolução desse indicador no período estudado, foi possivel perceber que ele passou de 0,38 horas de capacitação para 6,08 horas/ de capacitação por 1000 trabalhadores da Saúde após a implementação do novo modelo de gestão $(p=0,02)$. Com as ações educativas de treinamento, o número de trabalhadores considerados capacitados também variou de 5,84 para $7,54 /$ por CIHDOTT $(p<0,001)$.

A ampliação da demanda por notificações, captações e coordenação da logística da distribuição de órgãos também induziu o crescimento do número de trabalhadores na CNCDO-SC. O indicador criado para monitorar essa variável, que relacionou o número de trabalhadores da CNCDO-SC ao total dos servidores em função administrativa na SESSC no período estudado, apesar do aumento da equipe (que passou de oito servidores em 2002 para 19 servidores em 2014), passou de $3,61 \%$ antes da implantação do modelo espanhol para $2,76 \%$, índice este que não obteve significância relativa no estudo $(p=0,68)$.

O objetivo de uma central de notificação, doação, captação e distribuição de órgãos e tecidos (CNCDO) é oferecer o maior número possível de órgãos com a maior qualidade possível para as equipes de transplantes operarem no máximo de sua capacidade. Assim, as informações relacionadas às taxas de notificações, doações e captações foram consideradas indicadores de resultado nesta pesquisa e estão apresentadas na Tabela 2.

O número de protocolos de doação representados pela Taxa de Notificação de ME partiu da média de 27,91 protocolos por milhão de população- pmp no primeiro período para 55,3 protocolos pmp após a implantação da nova gestão $(p=0,001)$.

A taxa de captação de órgãos em SC passou de 33,5 para 41,12 no segundo período estudado ( $p=0,004$ ), bem como a retirada de múltiplos órgãos, que passou da média de 72,59 para 81,94 em 2008 a 2014, valor este que não se mostrou significativo $(p=0,19)$. 
Tabela 2 - Taxas médias de notificação, doação e captação de órgãos. Santa Catarina, 2002-2014.

\begin{tabular}{|c|c|c|c|}
\hline $\begin{array}{l}\text { Período } \\
\text { Indicadores de resultado }\end{array}$ & $\begin{array}{c}\text { 2002-2007 } \\
\text { Taxa e DP }\end{array}$ & $\begin{array}{c}\text { 2008-2014 } \\
\text { Taxa e DP }\end{array}$ & Valor de $p$ \\
\hline Tx de notificação de Morte Encefálica & $27,91 \pm 11,72$ & $55,3 \pm 10,75$ & 0,001 \\
\hline Tx de captação de órgãos & $33,5 \pm 4,12$ & $41,12 \pm 2,2$ & 0,004 \\
\hline Tx de Retirada de Múltiplos Órgãos & $72,59 \pm 14,35$ & $81,94 \pm 7,22$ & 0,19 \\
\hline Tx de transplante renal & $13,64 \pm 6,79$ & $33,05 \pm 3,83$ & $<0,001$ \\
\hline Tx de transplante rim/pâncreas & $0,02 \pm 0,06$ & $1,07 \pm 0,41$ & $<0,001$ \\
\hline Tx de transplante hepático & $5,09 \pm 4,19$ & $16,27 \pm 1,37$ & 0,001 \\
\hline Tx de transplante cardíaco & $0,48 \pm 0,28$ & $0,24 \pm 0,27$ & 0,146 \\
\hline Tx de transplante de córnea & $36,13 \pm 11,64$ & $74,36 \pm 19,9$ & 0,002 \\
\hline Tx de falha por PCR & $15,09 \pm 3,59$ & $22,58 \pm 4,28$ & 0,006 \\
\hline Tx de falha por recusa familiar & $36,82 \pm 5,39$ & $28,95 \pm 2,76$ & 0,14 \\
\hline Tx de falha por contraindicação clínica & $14,57 \pm 3,59$ & $6,86 \pm 3,2$ & 0,002 \\
\hline
\end{tabular}

Fonte: CNCDO-SC, adaptados pelo autor, 2016

Tx - Taxa por milhão de população (pmp); PCR - Parada Cardiorrespiratória; SC - Santa Catarina

A taxa de transplante renal passou de 13,64 pmp para $33,05 \mathrm{pmp}(\mathrm{p}<0,001)$ e a taxa de transplantes de rim e pâncreas foi de 0,02 pmp para $1,07 \mathrm{pmp}$, após a implantação do novo modelo de gestão $(p<0,001)$.

A taxa de transplante hepático passou da média de 5,09 pmp para 16,27 pmp após a implantação do modelo espanhol $(p=0,001)$ e a taxa de transplante cardíaco, passou de 0,48 pmp para 0,24 pmp ( $p=0,146)$.

Quanto ao transplante de córnea, a evolução na taxa de transplante foi de 36,13 pmp para 74,36 pmp, após o ano de 2007.

A taxa de falha de captação por PCR partiu da média de $15,09 \%$ para $22,58 \%$, um aumento significativo após a implantação da gestão ( $p=0,006)$.

O número de recusas familiares ao processo de doação passou de $36,82 \%$ para $28,95 \%$ após a nova gestão, mas não apresentou significância para o estudo $(p=0,14)$.

A taxa de recusas de doação por contraindicação clínica, criada a partir da divisão do número absoluto de contraindicações clínicas pelo total de notificações de $\mathrm{ME}$, que era de $14,57 \%$ no período anterior à implantação do modelo espanhol, caiu significativamente para $6,86 \%$ após $2008(p=0,002)$.

\section{DISCUSSÃO}

Este estudo teve como propósito analisar o processo de implantação de ações de gestão associadas com o "modelo Espanhol", implantado em SC a partir de 2007, comparando os resultados obtidos pelo sistema e a magnitude das açōes gerenciais executadas nesse período aos do período anterior (2002-2007), no qual a gestão não tinha um padrão característico e pautava-se mais por ações de caráter reativo do que por qualquer outra referência teórica. A mensuração das ações executadas e dos resultados alcançados foi feita a partir da criação de taxas que pudessem dimensionar o impacto causado, positivo ou não, pela adoção do novo modelo.

Esta discussão aborda os fatores que foram considerados mais relevantes para uma avaliação mais precisa da gestão sob análise, como o número de notificações de ME, redução nas negativas de doação e taxas individuais na doação de órgãos como rim, fígado, córnea, entre outros.

Os dados obtidos na GETRA foram comparados aos dados gerais do IBGE e da ABTO (Associação Brasileira de Transplante de Órgãos), a fim de criar uma média 
capaz de comparar as mudanças ocorridas em Santa Catarina em relação aos valores obtidos pelo país como um todo.

É importante observar inicialmente que a taxa de trabalhadores efetivos da CNCDO-SC não apresentou significância estatística quando comparada à dos dois períodos de estudo, visto que seu aumento não acompanhou o crescimento acelerado do número de trabalhadores contratados na área da Saúde. Esse fato deve-se, muito provavelmente, a uma gestão eficiente, onde mesmo com o aumento da demanda do serviço e da área de atuação da Central (discutidos no decorrer do estudo) não houve necessidade de muitas contratações, mas sim, de treinamento adequado com evidente ganho de produtividade.

Outra variável que não apresentou significância estatística neste estudo foi a taxa de negativa de doação por recusa familiar. Segundo Matesanz et al, ${ }^{17}$ mesmo após a implantação do novo sistema de gestão focado no treinamento da abordagem familiar sobre a morte e a possibilidade de doação na Espanha, não houve grandes mudanças nas taxas de recusa familiar, que variaram entre 20 e $25 \%$ do número de possíveis doadores. Uma pesquisa realizada também na Espanha revelou que $78 \%$ das recusas familiares mudaram de ideia após uma conversa franca com o coordenador de transplante, ${ }^{18}$ o que demonstra que ainda existe espaço significativo para melhorar a abordagem familiar, o que pode aumentar as taxas de doação.

O número de hospitais com comissões internas responsáveis pela coordenação do processo de doação de órgãos também se mostrou uma variável positiva na mensuração da qualidade de gestão em Santa Catarina. Em outro estudo realizado na Espanha ${ }^{19}$ após a implantação do modelo, indicou que houve acréscimo de 150 hospitais notificantes no país num período de 20 anos. No presente estudo, observamos que antes do modelo espanhol, as taxas de hospitais notificantes em SC variavam em torno de 9,44, elevando-se para uma média de 15,25 após sua implantação.

Nesse contexto, o treinamento foi um componente essencial do sucesso do modelo espanhol. ${ }^{19}$ Cursos foram oferecidos na Espanha para profissionais envolvidos direta ou indiretamente no processo de doação, somando 11 mil funcionários contemplados entre 1991 e 2010. Em Santa Catarina, o presente estudo também evidenciou um aumento significativo nas horas/ curso oferecidas para cada 1000 (um mil) trabalhadores da Saúde, passando de uma média de 0,38 horas/curso entre 2002 e 2007 para 6,08 entre 2008 e 2014.

Rafael Matesanz ${ }^{20}$ menciona a experiência na Toscana, onde o treinamento específico dos membros da comissão de transplantes contribuiu para o aumento significativo na taxa de doadores, que atingiu valores como 30 doadores pmp. No presente estudo, observamos que a taxa de trabalhadores das CIHDOTTs cresceu paralelamente à taxa de trabalhadores capacitados das CIHDOTTs, evoluindo de valores de 5,84 entre 2002 e 2007 para 7,54 entre 2008 e 2014. Esses dados comprovam a eficácia do modelo de gestão adotado, que ao garantir a oferta de mais treinamentos para membros das equipes de transplantes, pode ter incluído um fator responsável pelo destaque de SC no número de doadores pmp.

Salim et al ${ }^{21}$ demonstraram aumento de $57 \%$ nas taxas de notificação de ME através de uma política denominada ADM (Agressive Donor Management) com enfoque no cuidado intensivo, ressuscitação de fluidos, uso precoce de vasopressores e prevenção de complicações após a ME. Em SC, podemos observar após a implantação do novo modelo de gestão e do treinamento constante dos envolvidos no processo de notificação e doação de órgãos um aumento nas taxas de notificação de $\mathrm{ME}$, que partiu de uma média de 27,91 entre 2002 e 2007 e alcançou média de 55,3 entre 2008 e 2014.

A implantação do modelo espanhol gerou resultados positivos no número de captações também em outros países, como Portugal e Croácia, ${ }^{19}$ onde as taxas de captação cresceram 37 e 54\%, respectivamente, entre 2006 e 2009. No presente estudo, podemos observar um aumento importante nas taxas de captação de órgãos em SC após a implantação do modelo, crescendo de uma média de 33,5\% entre 2002 e 2007 para 41,12\% entre 2008 e 2014.

A Espanha apresentou em 2002 taxas de doação de rim com valores em torno de 50,6 doações pmp (por milhão de população). ${ }^{18} \mathrm{O}$ presente estudo demonstrou um aumento crítico no número de transplantes renais pmp em SC, partindo de uma taxa de 13,64 entre 2002 e 2007 para 33,05 entre 2008 e 2014, crescendo 2,4 vezes após a implantação da nova gestão.

O mesmo estudo ${ }^{18}$ também apontou uma taxa de 24,2 transplantes hepáticos pmp em 2002 na Espanha. No presente estudo, podemos constatar que entre 2002 e 2007, as taxas de transplante hepático permeavam em torno de 5,09 pmp, e após a implantação do modelo espanhol entre 2008 e 2014, as taxas subiram para 16,27 pmp, um aumento de 3,19 vezes.

Westphal et al ${ }^{22}$ buscou avaliar o efeito na taxa de captação de órgãos através de um protocolo de manutenção de potenciais doadores de múltiplos órgãos em um hospital de SC com metas de tempo para os exames (gráficos e clínicos), hemodinâmicas, ventilatórias, endocrino-metabólicas, entre outras. Foram obtidos resultados positivos na redução de $27,8 \%$ 
de perda por PCR para $0 \%$ e aumento de $44,4 \%$ para $75 \%$ de doadores reais. Neste estudo, que não avaliou apenas os resultados de um serviço, mas o total de SC, podemos observar que houve aumento nas taxas de perda por PCR após a implantação do modelo espanhol no estado, iniciando com uma média de $15,09 \%$ para $22,58 \%$, o que reforça ainda mais que as medidas discutidas por Westphal devem ser implantadas em todos os hospitais brasileiros a fim de impulsionar a eficiência do processo de transplante de órgãos.

Através do treinamento das equipes responsáveis pela manutenção de pacientes críticos e de estratégias como as propostas por Westphal et al ${ }^{22}$ para o manejo do potencial doador, também observamos uma redução importante nas falhas de captação por contraindicação clínica, que se reduziram de 14,57 entre 2002 e 2007 para 6,86 de 2008 a 2014.

Outro modo de salientar o desempenho de Santa Catarina com a implantação do Modelo Espanhol de gestão de transplantes foi pela comparação dos dados do estado com a média Brasileira em diversos indicadores. Segundo o Registro Brasileiro de Transplantes (RBT), ${ }^{23}$ a média de transplantes renais de doadores falecidos pmp no Brasil no período entre 2008 e 2014 foi de 17,5. O presente estudo revelou que, no período entre 2008 e 2014, quando o Modelo Espanhol encontrava-se em vigência, a média foi de $33,05 \mathrm{pmp}, 88 \%$ maior que a média brasileira.

O RBT ${ }^{23,24}$ também registrou uma média de doações hepáticas pmp no Brasil de 5,2 entre 2002 e 2007, passando para 7,9 entre 2008 e 2014. Em SC, o atual estudo revelou que, de uma média muito próxima do resto do país (5,09 doações pmp), o estado alcançou média de 16,27 doações hepáticas pmp. Observa-se que enquanto o país teve crescimento 1,5 vezes maior, o crescimento das doações no estado de SC foi 3,19 vezes maior no mesmo período.

Já em relação às recusas por contraindicação clínica, o RBT 23,24 informou que entre 2002 e 2007 a média brasileira, que era de $39,5 \%$ passou para média de $14,11 \%$ no período entre 2008 e 2014, correspondente à redução de $35,7 \%$ desses valores. Em SC, o presente estudo mostrou que o estado apresentou média de $14,57 \%$ de recusas por contraindicação clínica no primeiro período, tendo recuado para $6,86 \%$ no segundo período, com redução de $47,1 \%$ dos valores médios do período anterior à implantação do novo modelo de gestão. É evidente que as comparações nesse caso são mais difíceis, já que muitas vezes as grandes perdas têm motivos facilmente identificáveis, produzindo efeitos imediatos e significativos quando enfrentados. Quando as taxas de recusa vão se reduzindo, suas causas, em geral, tornamse mais difíceis de reconhecer e exigem mais recursos para seu enfrentamento. Enfim, as curvas de queda de indicadores, em geral, não são lineares, mas indicaram que Santa Catarina manteve a tendência de melhoria de indicadores, mesmo tendo taxas baixas como referência inicial.

O que parece nítido é que o processo de melhoria de resultados iniciado em 2007 em Santa Catarina permaneceu produzindo efeitos até o final do período estudado, destacando o serviço de captação, doação, distribuição e transplante de orgãos e tecidos no estado entre os demais do país e transformando-o em uma referência para os demais estados interessados em obter resultados mais efetivos em seus territórios.

Outra dificuldade que a doação de órgãos enfrenta é a ignorância da sociedade sobre o assunto, e por isso, a conscientização sobre o tema é importante, principalmente com o esclarecimento do complexo processo do ato de doar, desmistificando-o e tornando-o um ato generoso, consciente e solidário com o próximo, iniciativa que cabe aos profissionais de saúde e às Organizações da Sociedade Civil (OSC) que são favoráveis à causa. ${ }^{2}$

\section{CONCLUSÃO}

Os indicadores criados neste estudo para caracterizar medidas associadas à implantação de um modelo de gestão descentralizado do processo de notificação, captação e distribuição de orgãos, sob responsabilidade de equipes em cada hospital do estado, mas com forte presença da coordenação regional confirmaram o acerto de algumas decisões tomadas pela CNCDOSC. Entre estas, salientamos o aumento do número de hospitais notificantes de $M E$, ênfase na organização das CIHDOTTs, a oferta ampliada de treinamentos e capacitações gerais e especializadas oferecida aos membros dessas comissões e o acompanhamento rigoroso dos potenciais doadores em todos os hospitais do estado e sua transformação em doações efetivadas, sem dúvida, aspectos que produziram resultados melhores a cada ano do período estudado.

As taxas criadas para quantificar as medidas de gestão, como descritas acima e as já existentes para expressar o impacto nos resultados do sistema indicaram desempenho notável das taxas de notificação de ME, da captação de órgãos, das taxas de transplantes de córnea e fígado, e principalmente dos transplantes renais quando comparados os dois períodos distintos da gestão do sistema.

Conclui-se com este estudo que as decisões tomadas pela CNCDO-SC tendo como molde o Modelo Espanhol de Gestão em Transplante de Órgãos impactaram significativamente na qualidade do sistema, não acompanhando apenas o crescimento da média 
brasileira, mas superando seus valores e tornando SC referência nacional em transplante de órgãos e tecidos. $A$ replicação dessa estratégia por outras CNCDOs pode produzir resultados semelhantes nos demais estados da Federação, contribuindo para ampliar o acesso de pacientes em estado crítico de todo o país aos orgãos e tecidos de que necessitam para prolongar a vida com qualidade e tornando real o conceito que sustenta o Sistema Único de Saúde em nosso país: a saúde é um direito de todos e um dever do Estado.

\section{ABSTRACT}

Introduction: Since Adam gave his rib to Eve to the 1960s with the first kidney donation in Brazil, the organ transplantation grows as a therapeutic measure, and sometimes unique in several morbidities. In the 1980s, Spain began what would later be denominated the Spanish Model, placing that country as a reference in transplants worldwide. Purpose: To study aspects of the management / coordination of the Santa Catarina transplant system (CNCDO-SC) and its correlation with the results obtained in the reporting, donation, capture and use of organs in the State during the period of 2002-2014. Method: An ecological study that included all the population from Santa Catarina who had undergone brain death with CNCDO-SC notification or who had been receiving organ transplantation during the studied period, using information obtained from the CNCDO-SC records and the National Transplant System. The indicators represented the annual performance of the system, and they were described in average rates elaborated during the study. A division between the non-effect period of the action considered (2002-2007) and the effect during the period studied (2008-2014) was set. Results: Through the improvement in the performance introduced by the Spanish model on the considered management rates, an important increase in the outcome rates (notification, donation and organ harvesting) can be observed. Notifying Hospitals Rate in the pre- and post-implantation period of the model studied, with a mean of 9.44 between 2002-2007, which jumped to 15.25 between 2008 and 2014 (p $<0.001)$. The amount of training hours increased from 0.38 hours to 6.08 hours per 1000 health workers after the implementation of the new management model. Conclusion: The Spanish Management Model posed a significant impact on the improvement of the organ transplantation service in SC.

Keywords: Transplantation; Tissue donors, Organization and Administration; Ecological Studies.

\section{REFERENCES}

1. Lamb D. Transplante de Orgãos e Ética. Trad. Jorge Curbelo. São Paulo: Sociedade Brasileira de Vigilância de Medicamentos/Editora Hucitec, 2000.

2. Brasil. Ministério da Saúde. Secretaria de Gestão do Trabalho e da Educação na Saúde. Departamento de Gestão do Trabalho na Saúde. Técnico em hemoterapia: livro texto / Ministério da Saúde, Secretaria de Gestão do Trabalho e da Educação na Saúde, Departamento de Gestão da Educação na Saúde - Brasília: Ministério da Saúde, 2013. 7-8 p

3. Pêgo-Fernandes PM, Garcia VD. Estado atual do transplante no Brasil. Diagn Tratamento. 2010;15(2):51-2.
4. Knihs NS, Schirmer J, Roza BA. Adaptación del modelo español de gestión en trasplante para la mejora en la negativa familiar y mantenimiento del donante potencial. Texto contexto - enferm. [Internet]. 2011 [cited 2017 Mar 19] ; 20( spe ): 59-65. Available from: http://www. scielo.br/scielo.php?script=sci_arttext\&pid=S010407072011000500007\&lng=en. http://dx.doi.org/10.1590/ S0104-07072011000500007.

5. Dalbem GG, Caregnato RCA. Doação de órgãos e tecidos para transplante: recusa das famílias. Texto contexto enferm. [Internet]. 2010;19(4):728-35 
6. Transplantes de órgãos no Brasil. Rev. Assoc. Med. Bras. [Internet]. 2003 Jan [cited 2016 Mar 13]; 49(1): 1-1. Available from: http://www.scielo.br/scielo.php?script=sci_ arttext\&pid=S0104-42302003000100001\&lng=en. http:// dx.doi.org/10.1590/S0104-42302003000100001.

7. Secretaria de Estado da Saúde de Santa Catarina, SC é destaque no ranking nacional em doação de órgãos. Disponível em: http://portalses.saude.sc.gov.br/index. php?option=com_content $\&$ view=article\&id=1373:sce-destaque-no-ranking-nacional-em-doacao-deorgaos\&catid=625\&ltemid=258 Acesso em 15 de junho de 2015

8. Organización Nacional de Transplantes, ¿En qué consiste exactamente el modelo español?. Disponível em: http:// www.ont.es/home/Paginas/Enqueconsiste.aspx Acesso em 07 de junho de 2015

9. Matesanz R, Dominguez-Gil B, Coll E, de la Rosa G, Marazuela R. Spanish experience as a leading country: What kind of measures we taken? Transpl Int. 2011;22:33343

10. Matesanz R. Factors that influence the development of an organ donation program. Transplant Proc. 2004;36:739-41

11. Matesanz R. Cadaveric organ donation: Comparison of legislation in various countries of Europe. Nephrol Dial Transplant. 1998;13:1631-5

12. Ley $20 / 2011$ de julio, del Registro Civil. Boletín Oficial del Estado, 22 de julio de 2011, núm. 175, p. 8146881502

13. Donación en asistolia en España: situacíon actual y recomendaciones. Documento de Consenso [consultado em 13 de Mar de 2016]. Disponível em: http://www.ont.es/ infesp/DocumentosDeConsenso/DONACI\%C3\%93N\%20 EN\%20ASISTOLIA\%20EN\%20ESPA\%C3\%91A.\%20 SITUACI\%C3\%93N\%20ACTUAL\%20Y\%20 RECOMENDACIONES.pdf

14. Matesanz R (ed.). El modelo español de coordinación y trasplantes. 2. ed. Madrid: Aula Medica Ediciones, 2008.
15. Brasil. Conselho Federal de Medicina. Resolução $n^{\circ}$ 1.480/97 [citado 24 Jun 2017]. Disponível em: http://www. portalmedico.org.br/resolucoes/cfm/1997/1480_1997.htm

16. Brasil. Conselho Federal de Medicina. Resolução CFM no 2173/2017. [citado 24 Mar 2017]. Disponível https://sistemas. cfm.org.br/normas/visualizar/resolucoes/BR/2017/2173

17. Matesanz R. Factors that influence the development of an organ donation program. Transplant Proc. 2004;36(3):739-41.

18. López I, Rodríguez E. The Spanish model. New Left Rev [Internet]. 2011;XXI(69):5-28. Available from: http://www. miguelangelmartinez.net/IMG/pdf/2011_Lopez_Rodriguez_ Spanish_model_NLR.pdf।npapers3://püblication/ uuid/28165E9F-B3C6-4235-914B-4E7EF5A17B27

19. Matesanz R, Domínguez-Gil B, Coll E, De La Rosa $G$, Marazuela R. Spanish experience as a leading country: What kind of measures were taken? Transpl Int. 2011;24(4):333-43.

20. Matesanz R. Organ donation, transplantation, and mass media. Transplant Proc. 2003;35(3):987-9.

21. Salim A, Velmahos GC, Brown C, Belzberg $H$, Demetriades D. Aggressive organ donor management significantly increases the number of organs available for transplantation. J Trauma. 2005;58(5):991-4.

22. Westphal GA, Zaclikevis VR, Vieira KD, Cordeiro R de B, Horner MBW, Oliveira TP de, et al. Protocolo gerenciado de tratamento do potencial doador falecido reduz incidência de parada cardíaca antes do explante dos órgãos. Rev Bras Ter Intensiva [Internet]. 2012;24(3):334-40. Available from: http://www.scielo.br/scielo.php?script=sci_ arttext\&pid=S0103-507X2012000400007\&lang=pt

23. Abto. Dimensionamento dos Transplantes no Brasil e em cada estado (2005-2015). Regist Bras Transplantes-Veículo Of da Assoc Bras Transpl Órgãos [Internet]. 2015;21(1):88. Available from: http://www.abto.org.br/abtov03/Upload/file/ RBT/2015/rbt201508052015-lib.pdf $\backslash n 15$

24. Associação Brasileira de Transplante de Órgãos (ABTO). RBT- Registro Brasileiro de Transplantes 2008. 2008;45. 